Case report

Perinatology Vol. 31, No. 2, June, 2020 https://doi.org/10.14734/PN.2020.31.2.90

\section{Soo Jung Kim, MD', Ha Young Yun, MD', Soon-Sup Shim, MD², Hye-Sim Kang, MD', Chang Lim Hyun, MD ${ }^{3}$}

'Department of Obstetrics and Gynecology, Ewha Womans University Mokdong Hospital, Seoul; Departments of ${ }^{2}$ Obstetrics and Gynecology, ${ }^{3}$ Pathology, Jeju National University Hospital, Jeju, Korea

\title{
Placental Mesenchymal Dysplasia Associated with Placenta Previa and Preterm Labor
}

Placental mesenchymal dysplasia is a rare placental vascular anomaly characterized by placentomegaly and grape-like vesicles and is recently recognized condition. This resembles partial molar pregnancy by ultrasonography. Placental mesenchymal dysplasia may be associated with adverse complications such as prematurity and intrauterine growth restriction. If placental mesenchymal dysplasia is suspected after antenatal ultrasonography, a serial fetal surveillance should be provided. The placenta should be sent for pathological evaluation after delivery for confirmation of placental mesenchymal dysplasia. A 34 year-old nulliparous woman was referred to Jeju National University Hospital at 24 weeks 3 days of gestation because of preterm vaginal bleeding and multiple cysts in the placenta with previa marginalis by prenatal ultrasonography. At 26 weeks 2 days of gestation, uncontrolled vaginal bleeding and preterm labor ensued, and emergency cesarean section was done. After delivery, histopathologic result of the placenta was placental mesenchymal dysplasia and acute chorioamnionitis. We have described a case complicated with placental mesenchymal dysplasia associated with placenta previa and preterm labor.

Key Words: Placental mesenchymal dysplasia, Placenta previa, Preterm labor

\section{서론}

Received: 4 October 2019

Revised: 10 January 2020

Accepted: 15 January 2020

Correspondence to

Soo Jung Kim, MD

Department of Obstetrics and

Gynecology, Ewha Womans

University Mokdong Hospital, 1071

Anyangcheon-ro, Yangcheon-gu,

Seoul 07985, Korea

Tel: +82-2-2650-5274

Fax: +82-2-2647-9860

E-mail: bossksj@hanmail.net

Copyright@ 2020 by The Korean Society of Perinatology

This is an Open Access article distributed under the terms of the Creative Commons Attribution Non-Commercial License (http://creativecommons.org/ license/by-nc/4.0/), which permits unrestricted non-commercial use, distribution, and reproduction in any medium, provided that the original work is properly cited.

태반중간엽형성이상(placental mesenchymal dysplasia)은 드문 태반 질환으로, 거대태반 및 포도송이 양상의 소낭을 특징으로 하는, 부분 포상기태(partial hydatidiform mole)와 비슷 한 초음파 소견을 보인다. ${ }^{1}$ 태반중간엽형성이상의 경우 이배수체(diploid)의 정상 소견을 보 이며 조직학적 검사상 영양막 증식(trophoblastic hyperplasia)이 보이지 않아 부분 포상기태 와는 구별된다. ${ }^{2}$ 부분 포상기태는 양성의 임신성 영양막 질환의 하나이고 삼배수체(triploid) 이며 태아 기형과 연관이 있다. ${ }^{3}$ 태반중간엽형성이상의 빈도는 약 $0.02 \%$ 정도이며 여아에서 발생 빈도가 높다. ${ }^{4}$ 태반중간엽형성이상이 생기는 원인은 아직 명확하게 밝혀지지는 않았지 만 여러 가지 가설이 있다. 태아 성장 제한 등 태반중간엽형성이상에서 발생할 수 있는 합병 증에 대해서도 논의되고 있다. ${ }^{5,6}$ 이에 저자들은 산전 초음파상 포도송이 양상의 소낭이 보이 는 태반 소견으로 부분 포상기태 가능성이 있는 전치태반을 가진 산모가 조산 후 태반중간엽 형성이상으로 태반 병리 결과로 확인된 1예를 경험하였기에 고찰과 함께 보고하고자 한다.

\section{증례}

\section{1. 산모 증례}

병력: 34 세의 미분만부가 재태 연령 24 주 3 일에 질 출혈을 주소로 본원으로 전원되었다. 내원 전 타원에서 시행한 산전 초음파상 전치태반 및 부분 포상기태 가능성을 보였다. 본원에 내원하여 시행한 산전 초음파에서도 태반의 좌측은 정상적인 태반 모양을 보였으나 태반의 뒤쪽은 전층에 걸쳐 여러 개의 낭종 모양을 보여 포상기태에서 관찰할 수 있는 소견과 유사하 게 보였으며, 태반 두께가 $6.4 \mathrm{~cm}$ 로 두꺼웠고, 이 부분이 자궁경부까지 위치하여 전치태반처 
럼 보였다(Fig. 1). 산모의 다른 특이 병력 및 가족력은 없었다.

경과: 임신 17 주 3 일에 타원에서 시행한 사중표지물질검사 (quad test)상 다운증후군의 가능성은 1:580, 모체혈청 $a$-태 아단백(a-fetoprotein) 수치는 $1.39 \mathrm{MoM}$ 이었다. 산모는 임신 20 주 2 일에 처음 질 출혈이 시작되었고 이 때 자궁경부 용종이 발견되어 경과 관찰을 하다가 22 주 4 일에 자궁경부 용종 절제술 을 받았고 병리검사상 자궁경관 내 용종 소견이었다. 그 후 간헐 적으로 질 출혈이 있었으며 23주부터 24주까지 타원에서 입원 하여 경과 관찰을 하였다. 임신 24 주 3 일에 질 출혈 및 조기 진통 (preterm labor)이 지속되어 본원 산부인과로 전원되어 자궁수 축억제제를 사용하였다. 입원 당시 활력 징후는 혈압 109/75 $\mathrm{mmHg}$, 맥박수 84 회/분, 호흡수 20 회/분, 체온 $36.7^{\circ} \mathrm{C}$ 였고, 소변 검사상 특이 소견은 없었다. 임신 25주에 시행한 베타 사람융모 성생식샘자극호르몬( $\beta$-human chorionic gonadotropin) 수치 는 $22,235 \mathrm{mIU} / \mathrm{mL}$ 였다. 경과 관찰 중 임신 26 주 2 일에 조기 진 통 및 질 출혈이 지속되어 전치태반 소견으로 응급 제왕절개술 을 시행하여 $910 \mathrm{~g}$ 의 여아를 분만하였고, 1 분 및 5 분 아프가 점 수는 각각 3점, 7점이었다. 육안적으로 보이는 태반은 부분 포상 기태 같아 보였다. 탯줄 동맥혈 가스분석검사(arterial blood gas analysis)는 pH 7.350, $\mathrm{pCO}_{2} 41.4 \mathrm{mmHg}, \mathrm{pO}_{2} 21.2 \mathrm{mmHg}$, $\mathrm{HCO}_{3}{ }^{-} 21.2 \mathrm{mEq} / \mathrm{L}$, standard base excess $-2.5 \mathrm{mmol} / \mathrm{L}$ 였다. 베타 사람융모성생식샘자극호르몬 수치는 분만 후 1 일에 1,932 $\mathrm{mIU} / \mathrm{mL}$, 분만 후 5 일에 $167.7 \mathrm{mIU} / \mathrm{mL}$, 분만 후 12 일에 15.87 $\mathrm{mIU} / \mathrm{mL}$, 분만 후 한 달째에는 $1.49 \mathrm{mIU} / \mathrm{mL}$ 로 감소하였다. 산 모는 수술 후 특별한 문제 없이 회복하였다.

병리 소견: 태반의 병리학적 소견은 육안상으로 크기는 18.0× $14.0 \times 4.5 \mathrm{~cm}$, 무게는 $672 \mathrm{~g}$ 으로 정상보다 큰 편이었으며, 탯줄 은 길이가 $37 \mathrm{~cm}$, 직경은 $1 \mathrm{~cm}$ 였다. 현미경 소견으로는 줄기 융

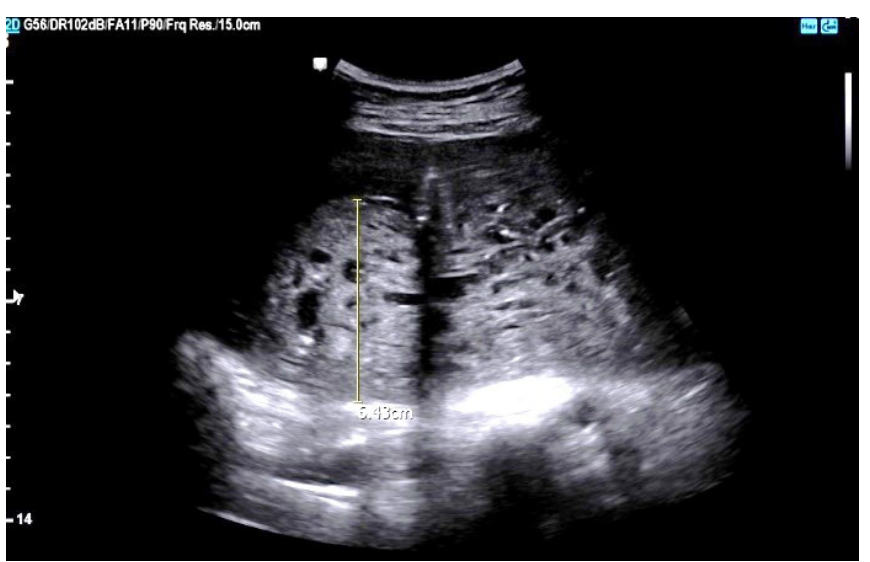

Fig. 1. Transabdominal ultrasonography scan at $24+3$ weeks' gestation shows a thickened placenta $(6.4 \mathrm{~cm})$ with multiple hypoechoic cysts, which suggests a possibility of partial hydatidiform mole. 모(stem villi)는 낭성으로 커져 있었으나 비정상적인 영양막 증 식(trophoblastic hyperplasia)이나 기질 내 영양막 세포 포함물 (stromal trophoblastic inclusion)은 관찰되지 않았다. 그리고 포 도송이 양상의 개별적인 소낭(vesicle)이 보였으며 태반중간엽 형성이상 및 급성 융모양막염 소견을 보였다(Fig. 2).

\section{2. 신생아 경과}

출생력: 환아는 재태 연령 26 주 2 일에 출생 체중 $910 \mathrm{~g}$ 의 여아 로 출생 직후 울음과 움직임이 미약하고, 청색증이 보이며, 호흡 노력이 없어 기관 삽관 후 본원 신생아 중환자실로 입원하였다.

이학적 소견: 신생아 집중치료실에 입원 당시 활력 징후는 맥 박수 165 회/분, 호흡수 61 회/분, 체온 $35.7^{\circ} \mathrm{C}$ 이며, 산소포화도는 $100 \%$ 로 측정되었다. 신체검사에서는 대천문의 함몰이나 팽창 은 없었으며 흉벽 함몰이 관찰되고 복부 팽만은 없었다.

검사 소견: 입원 당시 시행한 말초혈액검사에서 백혈구 $11,200 / \mathrm{\mu L}$ (중성구 $44.1 \%$, 림프구 $48.6 \%$, 단핵구 $4.1 \%$, 호산구 $1.9 \%$ ), 혈색소 $13.7 \mathrm{~g} / \mathrm{dL}$, 적혈구용적률 $38.7 \%$, 혈소판 $227,000 /$ $\mu \mathrm{L}, \mathrm{C}$-반응단백 $0.01 \mathrm{mg} / \mathrm{dL}$ 였다. 혈청 $\mathrm{Na}^{+} 141 \mathrm{mmol} / \mathrm{L}, \mathrm{K}^{+} 3.7$ $\mathrm{mmol} / \mathrm{L}, \mathrm{Ca}^{2+} 1.47 \mathrm{mg} / \mathrm{dL}$ 소견을 보였다. 출생 직후 혈당은 57 $\mathrm{mg} / \mathrm{dL}$ 로 측정되었다. 혈액 세균배양검사는 음성이었고 toxoplasmosis, rubella, cytomegalovirus, herpes 검사는 정상이었 다. 기관 삽관을 통하여 $3 \mathrm{~L} / \mathrm{min}$ 의 산소를 공급하면서 실시한 정 맥혈 가스분석검사에서 $\mathrm{pH} 7.295, \mathrm{pCO}_{2} 43.8 \mathrm{mmHg}, \mathrm{pO}_{2} 54$ $\mathrm{mmHg}, \mathrm{HCO}_{3}^{-} 21.3 \mathrm{mEq} / \mathrm{L}$, standard base excess $-5 \mathrm{mmol} / \mathrm{L}$ 로 대사성 산증 양상을 보였다. 흉부 방사선 사진에서는 양측 폐에

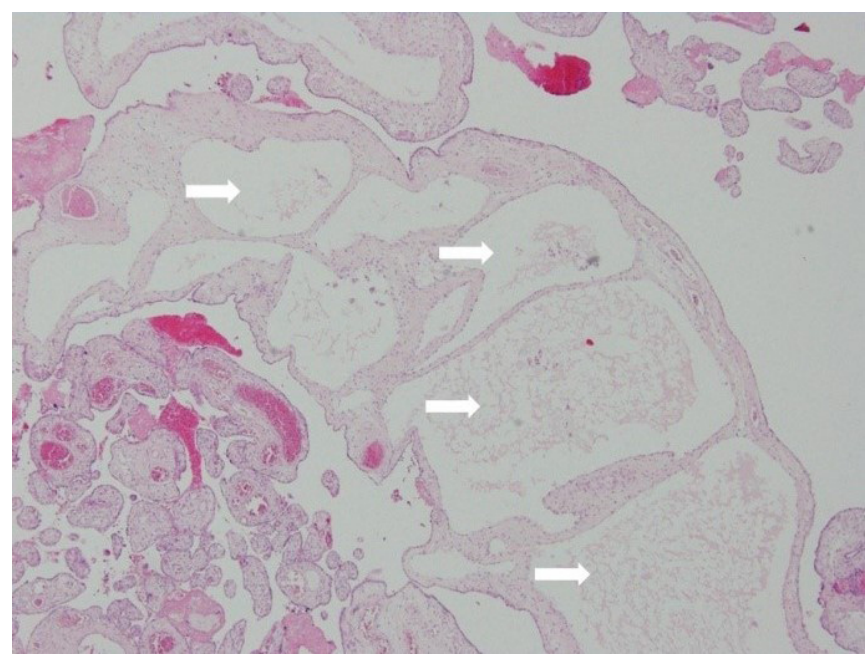

Fig. 2. Low-power magnification view of the placenta shows a mixture of normal and abnormal villi. Enlarged proximal stem villi with edematous stroma and cistern-like formation are seen (white arrows), whereas many villi are unremarkable. There is no trophoblastic hyperplasia (hematoxylin and eosin, $\times 40$ ). 
서 유리질막증 소견이 보였다. 환아는 초저출생체중아로 호흡곤 란 증후군, 뇌실내 출혈의 소견을 보였다.

경과: 환아는 출생 16 시간 후 갑작스럽게 서맥이 발생하고 산 소포화도 $40 \%$ 이하로 감소하여 심폐소생술을 1 시간 시행하였 으나 심박동수 및 산소포화도가 정상으로 회복되지 않은 채로 사망하였다.

\section{고찰}

태반중간엽형성이상은 비교적 최근에 발견된 태반 혈관 이상 질환으로 초음파상 부분 포상기태처럼 태반거대증(placentomegaly)이나 포도송이 양상의 소낭을 보인다. ${ }^{1}$ 1986년에 Takayama 등 ${ }^{7}$ 이 혈관 기형을 동반한 이상 태반으로 처음 보고 하였고, 1991년 Moscoso 등이 모체혈청 a-태아단백이 상승 하고 초음파상 태반이 크고 부분 포상기태처럼 보이는 2 개의 증례를 통하여 하나의 병리 질환으로 인식되었다. 이러한 병변 은 산전 초음파검사나 분만 후 육안적으로 본 태반이 포상기태 와 유사하며, 태반의 태아판(fetal plate) 쪽 혈관 기형이 동반되 거나 태반 실질에서 부분 포상기태와 유사하게 낭성 구조가 관 찰된다. ${ }^{3,8}$ 태반중간엽형성이상의 정확한 빈도는 알 수 없으나 2002년 Arizawa와 Nakayama ${ }^{4}$ 가 발표한 문헌에서는 약 $0.02 \%$ 정도로 보고하였고, 신생아 중 $80.5 \%$ 가 여아로 X 염색체 관련성 이 의심되었다.

태반중간엽형성이상이 생기는 원인은 아직 명확하게 밝혀지 지는 않았지만 여러 가지 가설이 있다. 먼저 태반중간엽형성이 상의 경우 혈관 기형이 동반되기도 하며, 그 종류로는 태반의 융 모막혈관종(chorioangioma), 태아 간실질의 과오종(hamarto- $\mathrm{ma}$ ), 피부혈관종(angioma) 등이 있다. 이를 통하여 발생 원인이 혈관 신생(neovascularization)이나 중간엽 발생 과정 중에 문제 가 생긴 것으로 의심될 수 있다. ${ }^{4,7}$ 임신 초기에 배아의 혈관 신생 에서 내막세포(endothelial cell)는 혈관내피성장인자(vascular endothelial growth factor)와 반응하여 성장과 분화를 하게 된 다. 이 혈관내피성장인자의 유전자가 최근 X 염색체에서 발견되 었고 Xp22.31에 위치한다. ${ }^{4.9}$ 이는 임상적으로 여아의 비율이 높 은 것과 X 염색체 관련성이 있음을 뒷받침하고, 발생학적으로 혈관 신생 과정의 이상이 병리기전의 하나로 가정되고 있다. 중 간엽형성이상을 보이는 부분은 비교적 혈관 신생이 적어 혈류 공급이 부족하게 되어 불균형이 생기고 임신 후기가 될수록 심 해진다고 생각된다. ${ }^{6,10}$ 그 다음 발생 원인으로는 태반중간엽형 성이상과 베크위드-비데만(Beckwith-Wiedemann) 증후군과 의 관련성이다. 이 증후군은 태아가 증식성 내장거대증(internal visceromegaly), 큰혀증(macroglossia), 배꼽탈장(exomphalos) 의 특징과 함께 태반거대증을 보인다. 유전적 원인으로 11 번 염 색체의 유전자 $11 \mathrm{p} 15.5$ 의 이상이 발견되었고, 이는 인슐린유사 성장인자(insulin-like growth factor-2)와 관련이 있다.,9 인슐 린유사성장인자가 억제되지 못하고 과발현되면서 과잉 성장이 나 거대증이 발생된 것으로 알려졌다. 태반중간엽형성이상의 경 우 표현형이 태반에만 국한되어 나타난 것이고, 베크위드-비데 만 증후군의 경우는 태반 및 태아에까지 영향을 미쳤다고 생각 하는 것이다. 그 다음으로 2006년 Kaiser-Rogers 등 ${ }^{11}$ 은 androgenetic/biparental 모자이크현상(mosaicism) 소견을 보 이는 두 증례를 보고하면서 다음과 같은 발병기전을 제시하였 다. 하나의 난자와 하나의 정자의 수정에서 첫 난할 시 이상으로 정상적인 양친(biparental)의 세포와 부계 유래 편친(paternalorigin uniparental)의 isodisomy 세포가 혼합된 모자이크현상이

Table 1. Differential Diagnosis of Placental Mesenchymal Dysplasia ${ }^{3,9,12,13}$

\begin{tabular}{|c|c|c|c|}
\hline & Placental mesenchymal dysplasia & Partial hydatidiform mole & $\begin{array}{l}\text { Complete hydatidiform mole coexistent with } \\
\text { normal cotwin }\end{array}$ \\
\hline Karyotype & Diploid & Triploid & Diploid \\
\hline Fetal structure & Normal or BWS & Abnormal & Normal \\
\hline Placental appearance & Thickened multicystic & Thickened multicystic & $\begin{array}{l}\text { Coexistence of normal and thickened multicystic } \\
\text { placentas }\end{array}$ \\
\hline Placental stem villous vessel & $\begin{array}{l}\text { Dilatation with aneurysmal and } \\
\text { chorioangiomatoid changes }\end{array}$ & Less dilatation & Dilatation \\
\hline Placental trophoblastic hyperplasia & Absent & Present & Present \\
\hline p57 staining & Present & Present & Absent \\
\hline
\end{tabular}

Abbreviations: $\beta$-hCG, $\beta$-human chorionic gonadotropin; BWS, Beckwith-Wiedemann syndrome. 
발생하고, 이후 부계의 편친의 isodisomy 세포가 주로 융모막중 배엽(chorionic mesoderm)에 존재하면서 융모 형성의 이상 소 견을 보이는 것이 태반중간엽형성이상이라는 것이다. 이들의 가 설에 따르면 여아에서 호발하는 특성과 이 이상세포가 태아 체 내에 일부 남아 있는 경우 각인(imprinting) 이상 소견으로 베크 위드-비데만 증후군 소견이 종종 동반되는 현상도 함께 설명할 수 있다.

태반중간엽형성이상은 산전 초음파상 부분 포상기태와 유사 하기 때문에 불필요한 인공 유산을 줄이기 위하여 감별 진단이 필요하다. 대부분의 부분 포상기태는 염색체 검사상 삼배수체이 며 태아는 기형을 동반하거나 유산되지만 태반중간엽형성이상 의 경우에는 이배수의 정상 소견을 보이며 모체혈청 $a-$ 태아단 백 수치는 증가하고, 베타 사람융모성생식샘자극호르몬 수치는 정상이며 영양막 증식이 없다. ${ }^{1,12}$ 태반중간엽형성이상, 부분 포 상기태, 정상 쌍태 임신과 동반된 완전 포상기태 사이의 감별점 은 Table 1 과 같다. ${ }^{3,9,12,13}$

태반중간엽형성이상과 관련하여 이야기되고 있는 태아 및 산 모 합병증으로는 자궁내성장제한(intrauterine growth restriction), 자궁내태아사망(intrauterine fetal death), 베크위드-비데 만 증후군, 조기 진통, 자간전증(preeclampsia) 등이 있다. ${ }^{5,6,10}$ 본 증례의 경우에는 산전 초음파상 부분 포상기태의 소견을 보 이는 전치태반을 가진 산모가 조기 진통 및 질 출혈로 인하여 26 주 2일에 조산하였으며, 태반 병리검사에서 태반중간엽형성 이상으로 확인되었다. 이 증례에서 나타난 조산이나 전치태반이 태반중간엽형성이상과 관련성이 있는지는 확실치 않다. 또한 신 생아 부검 및 유전자 검사가 이루어지지 않아 태아 사망이 태반 중간엽형성이상과 연관된 기형 소견과 관계가 있었는지, 단순히 조산으로 인한 것인지도 확실치 않다.

저자들은 산전 초음파상 부분 포상기태 가능성이 있는 전치태 반을 가진 산모가 조산 후 태반중간엽형성이상으로 확인된 증례 1 예를 경험하였기에 문헌고찰과 함께 보고하는 바이다. 산전 초 음파검사에서 정상적인 태아와 함께, 다발성 낭성 구조물이 보 이는 부분 포상기태와 유사한 태반이 관찰되는 경우에는 정기적 인 산전 초음파검사를 통하여 태아 기형이나 태아와 산모의 안 녕 및 태반 병변의 지속적인 관찰이 필요하다. 그리고 산전 염색 체 검사를 시행하여 이배수체의 정상 소견을 보인다면 태반중간 엽형성이상 가능성을 고려해야 한다. 분만할 경우에는 태반 병 리검사를 시행하여 정확한 병명을 확인하고 신생아 예후에 대한 장기적인 추적관찰이 필요하다.

\section{Conflict of interest}

No potential conflict of interest relevant to this article was reported.

\section{References}

1) Moscoso G, Jauniaux $E$, Hustin J. Placental vascular anomaly with diffuse mesenchymal stem villous hyperplasia. A new clinico-pathological entity? Pathol Res Pract 1991;187:324-8.

2) Robert JK, Lora HE, Brigitte MR, eds. Blaustein's pathology of the female genital tract. 6th ed. New York: Springer, 2011:1006.

3) Kim $Y H$, Jung DY, Lee $Y$, Park IY, Ahn HY, Ko HS, et al. A case of mesenchymal dysplasia of the placenta. Korean J Obstet Gynecol 2006; 49:436-42

4) Arizawa M, Nakayama M. Suspected involvement of the X chromosome in placental mesenchymal dysplasia. Congenit Anom (Kyoto) 2002;42: 309-17.

5) Nayeri UA, West AB, Grossetta Nardini HK, Copel JA, Sfakianaki AK. Systematic review of sonographic findings of placental mesenchymal dysplasia and subsequent pregnancy outcome. Ultrasound Obstet Gynecol 2013;41:366-74.

6) Pham T, Steele J, Stayboldt C, Chan L, Benirschke K. Placental mesenchymal dysplasia is associated with high rates of intrauterine growth restriction and fetal demise: a report of 11 new cases and a review of the literature. Am J Clin Pathol 2006;126:67-78.

7) Takayama M, Soma H, Yaguchi S, Funayama H, Fujiwara $K$, Irie $H$, et al. Abnormally large placenta associated with Beckwith-Wiedemann syndrome. Gynecol Obstet Invest 1986;22:165-8.

8) Na ED, Lee KJ, Kim MJ, Yi HJ, Kim JY. Placental mesenchymal dysplasia associated with severe preeclampsia: a case report. Korean J Obstet Gynecol 2011;54:459-63.

9) Parveen Z, Tongson-Ignacio JE, Fraser CR, Killeen JL, Thompson KS. Placental mesenchymal dysplasia. Arch Pathol Lab Med 2007;131:1317.

10) Heazell AE, Sahasrabudhe N, Grossmith AK, Martindale EA, Bhatia K. A case of intrauterine growth restriction in association with placental mesenchymal dysplasia with abnormal placental lymphatic develop ment. Placenta 2009;30:654-7.

11) Kaiser-Rogers KA, McFadden DE, Livasy CA, Dansereau J, Jiang R, Knops $J$ F, et al. Androgenetic/biparental mosaicism causes placental mesenchymal dysplasia. J Med Genet 2006:43:187-92.

12) Pawoo N, Heller DS. Placental mesenchymal dysplasia. Arch Pathol Lab Med 2014;138:1247-9.

13) Woo GW, Rocha FG, Gaspar-Oishi M, Bartholomew ML, Thompson KS. Placental mesenchymal dysplasia. Am J Obstet Gynecol 2011;205:e3-5. 